\title{
Partial splenic embolisation for hypersplenism of thalassaemia major: five year follow up
}

\author{
C POLITIS, D G SPIGOS, P GEORGIOPOULOU, H VRETTOU, I ECONOMIDOU, \\ A E GERMENIS, C RICHARDSON, G PAPAEVANGELOU
}

\begin{abstract}
Six patients with thalassaemia major were treated by partial splenic embolisation as an alternative to splenectomy and followed up for five years. Results were compared with those in a matched control group of seven patients treated by splenectomy.

All patients treated by partial splenic embolisation showed a reduction in blood transfusion requirements comparable with those in the controls and which remained unchanged over the five years. Serious infections that commonly occur in patients splenectomised for thalassaemia did not occur after embolisation, presumably owing to preservation of some immune function by the splenic remnant. By contrast with the change in platelet counts seen after splenectomy, platelet counts remained normal after partial splenic embolisation, so reducing the risk of thromboses. On the other hand, pre-existing leucopenia and thrombocytopenia were corrected after embolisation.

It is concluded that partial splenic embolisation provides an alternative to splenectomy for thalassaemia major and is equally effective and much safer.
\end{abstract}

\section{Introduction}

Overwhelming infections $\mathrm{s}^{1-3}$ and pulmonary artery embolism leading to hypoxaemia ${ }^{4}$ may occur even long after splenectomy for hypersplenism in thalassaemia major. In an attempt to avoid these

\author{
Hellenic Red Cross Thalassaemia Unit, GR-104 39 Athens, Greece \\ C POLITIS, $\mathrm{MD}$, associate professor of medicine \\ P GEORGIOPOULOU, MD, paediatrician \\ H VRETTOU, MD, paediatrician \\ I ECONOMIDOU, $M D$, associate professor of medicine \\ A E GERMENIS, MD, research fellow
}

Department of Medical Radiology, University of Illinois Hospital, Chicago, USA

D G SPIGOS, MD, professor of medical radiology

Athens School of Hygiene, Athens, Greece

C RICHARDSON, PHD, biostatistician

G PAPAEVANGELOU, MD, professor of epidemiology and medical statistics

Correspondence to: Dr Politis. complications of splenectomy we sought an alternative treatment which would reduce transfusion requirements of patients with thalassaemia while preserving splenic immune function. Partial splenic embolisation was therefore undertaken, for the first time internationally, in a small group of patients with thalassaemia major and the results up to five years after the procedure compared with those in another group of patients treated by splenectomy at about the same time.

\section{Patients and methods}

The study group comprised six patients aged 9-22 years (three men) who in 1979-80 presented with hypersplenism of thalassaemia major and were treated by partial splenic embolisation. The technique of embolisation was as described by Spigos $e t a l,{ }^{5}$ and informed consent was obtained in all instances.

All the patients had an enlarged spleen and were receiving transfusions every 14-21 days in an effort to maintain a haemoglobin concentration greater than $100 \mathrm{~g} / \mathrm{l}$. White cell and platelet counts were normal in all but one patient (case 1), who had severe leucopenia and thrombocytopenia and suffered recurrent nosebleeds and infections. Table I shows the proportion of spleen embolised in each case, estimated from angiograms (fig 1) and liver and spleen scans (fig 2) taken before and after the procedure. The first patient required two embolisations, 18 months apart, because of suboptimal infarction of the spleen (only $30 \%$ ) at the original procedure.

A group of seven patients with thalassaemia aged 6-14 who underwent splenectomy for hypersplenism at about the same time that the study group was treated served as controls. Both groups were treated with desferrioxamine and before the procedures were given a multivalent vaccine against pneumococci (Pneumovax) and after the procedures maintained with long term prophylactic penicillin.

Follow up of the study and control groups included assessments of clinical course and estimations of blood transfusion index (calculated as [ $\mathrm{ml}$ blood/days/body surface area $\left.\left(\mathrm{m}^{2}\right)\right]$ /[mean haemoglobin concentration]); mean pretransfusion haemoglobin concentration; leucocyte, platelet, and erythroblast counts; red cell survival time; serum immunoglobulin and ferritin concentrations; iron load; and spleen and liver size.

The significance of differences within and between the two groups of patients was estimated by multivariate analyses.

\section{Results}

A significant $(p<0.001)$ fall of the transfusion index was noted in both groups of patients one year after the procedures, and the index remained 
unchanged thereafter. Changes in mean haemoglobin concentration were not significant in either group, though a steady, small increase was detected during the years after partial splenic embolisation. There were no significant differences in transfusion index or haemoglobin concentration between the two groups either before or after the procedures (table II).

In the study group a small increase in mean leucocyte and platelet counts occurred immediately after embolisation, reaching a peak (leucocytes $10 \times 10^{9} / 1$; platelets $622 \times 10^{9} / 1$ ) during the second week and falling to normal over the next six months. Thereafter the counts remained normal. Only one
Changes in mean IgG and IgA concentrations were not detected in either $\underline{w}$ group of patients after the procedures. The mean $\operatorname{IgM}$ concentration, however, rose in the patients treated by partial splenic embolisation and remained significantly higher $(\mathbf{p}<0.005)$ than in the splenectomised group $\varrho$ till the fourth year, when IgM concentrations in that group also rose and the $c$ difference disappeared.

Serum ferritin concentrations were similar in the two treatment groups $\bar{J}$ before the procedures and increased by $68 \%$ during the first year. Over $D$ subsequent years concentrations declined, and at five years the mean $\mathbb{D}$

TABLE I-Proportion of spleen embolised in each patient with thalassaemia

\begin{tabular}{|c|c|c|c|c|c|}
\hline Case No & Sex & $\begin{array}{l}\text { Age at partial splenic embolisation } \\
\text { (years) }\end{array}$ & $\begin{array}{l}\text { White cell count } \\
\text { before partial splenic embolisation } \\
\left(\times 10^{9} / 1\right)\end{array}$ & $\begin{array}{c}\text { Platelet count } \\
\text { before partial splenic embolisation } \\
\left(\times 10^{9} /\right)\end{array}$ & $\begin{array}{c}\text { \% Of spleen } \\
\text { embolised }\end{array}$ \\
\hline 1 & $\mathbf{F}$ & 13 & $2 \cdot 0$ & 50 & $\left\{\begin{array}{l}30 \text { (first procedure) } \\
70 \text { (total) }\end{array}\right.$ \\
\hline $\begin{array}{l}2 \\
3 \\
4 \\
5 \\
6\end{array}$ & $\begin{array}{c}\mathbf{F} \\
\mathbf{M} \\
\mathbf{M} \\
\mathbf{F} \\
\mathbf{M}\end{array}$ & $\begin{array}{r}9 \\
15 \\
21 \\
22 \\
\quad 9\end{array}$ & $\begin{array}{r}5 \cdot 6 \\
6.3 \\
7.3 \\
6 \cdot 8 \\
5 \cdot 1\end{array}$ & $\begin{array}{l}210 \\
185 \\
235 \\
263 \\
198\end{array}$ & $\begin{array}{l}85 \\
90 \\
60 \\
90 \\
70\end{array}$ \\
\hline
\end{tabular}

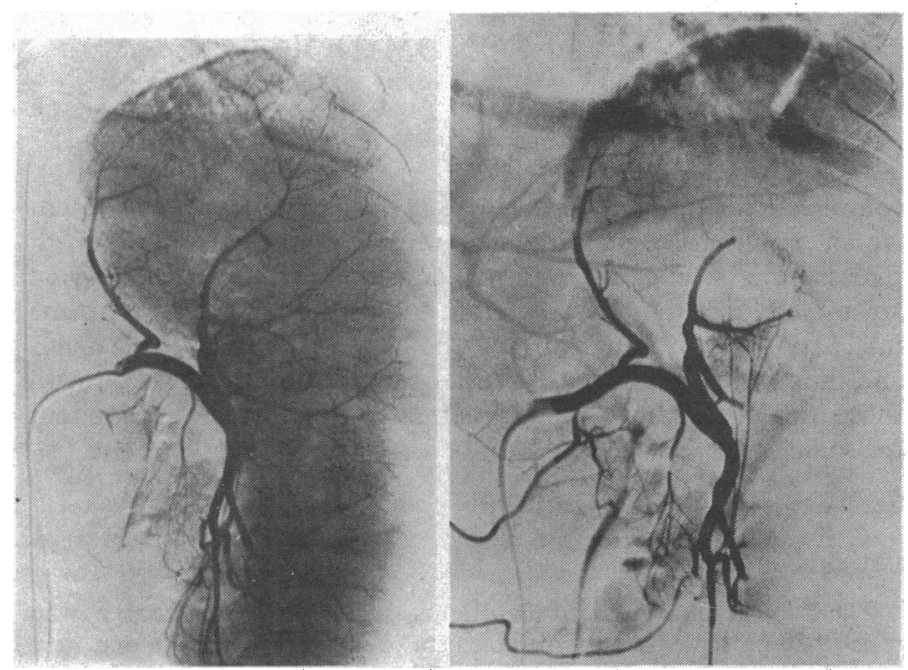

FIG 1-Case 3. Angiograms of spleen (arterial phase) before (left) and after (right) partial splenic embolisation. (In this case an estimated $90 \%$ of spleen was embolised.)

TABLE II-Mean blood transfusion indices and pretransfusion haemoglobin concentrations $(g / l)$ in patients before and in the years after partial splenic embolisation and splenectomy

\begin{tabular}{|c|c|c|c|c|c|}
\hline & \multirow{2}{*}{$\begin{array}{l}\text { Before } \\
\text { procedure }\end{array}$} & \multicolumn{4}{|c|}{ Year after procedure } \\
\hline & & lst & 2nd & 3rd & 4th \\
\hline $\begin{array}{l}\text { Transfusion } \\
\text { index }\end{array}\left\{\begin{array}{l}\text { Partial splenic embolisation } \\
\text { Splenectomy }\end{array}\right.$ & $\begin{array}{l}5 \cdot 14 \\
4 \cdot 72\end{array}$ & $\begin{array}{l}3 \cdot 52 \\
2 \cdot 43\end{array}$ & $\begin{array}{l}3 \cdot 41 \\
2 \cdot 13\end{array}$ & $\begin{array}{r}3 \cdot 30 \\
2 \cdot 13\end{array}$ & $\begin{array}{l}3 \cdot 39 \\
2 \cdot 29\end{array}$ \\
\hline Haemoglobin $\left\{\begin{array}{l}\text { Partial splenic embolisation } \\
\text { Splenectomy }\end{array}\right.$ & $\begin{array}{l}80 \cdot 8 \\
78 \cdot 6\end{array}$ & $\begin{array}{l}82 \cdot 8 \\
82 \cdot 0\end{array}$ & $\begin{array}{l}82 \cdot 9 \\
81 \cdot 7\end{array}$ & $\begin{array}{l}84 \cdot 2 \\
78 \cdot 4\end{array}$ & $\begin{array}{l}86 \cdot 8 \\
80 \cdot 7\end{array}$ \\
\hline
\end{tabular}

patient immediately after partial splenic embolisation had a platelet count four times the previous value, while in the patient with severe leucopenia and thrombocytopenia before embolisation both counts returned to normal. A small increase in numbers of erythroblasts also occurred immediately after partial splenic embolisation (range 12-46/100 leucocytes), the counts stabilising a few months later at a lower level (range 10-35/100 leucocytes).

By contrast, a substantial increase in leucocyte, platelet, and erythroblast counts occurred in the patients treated by splenectomy. The leucocytosis subsided gradually during the subsequent months but the platelet and erythroblasst counts remained raised at five years (mean platelet count $632140 \times 10^{6} / 1$; erythroblast counts 48-233/100 leucocytes)

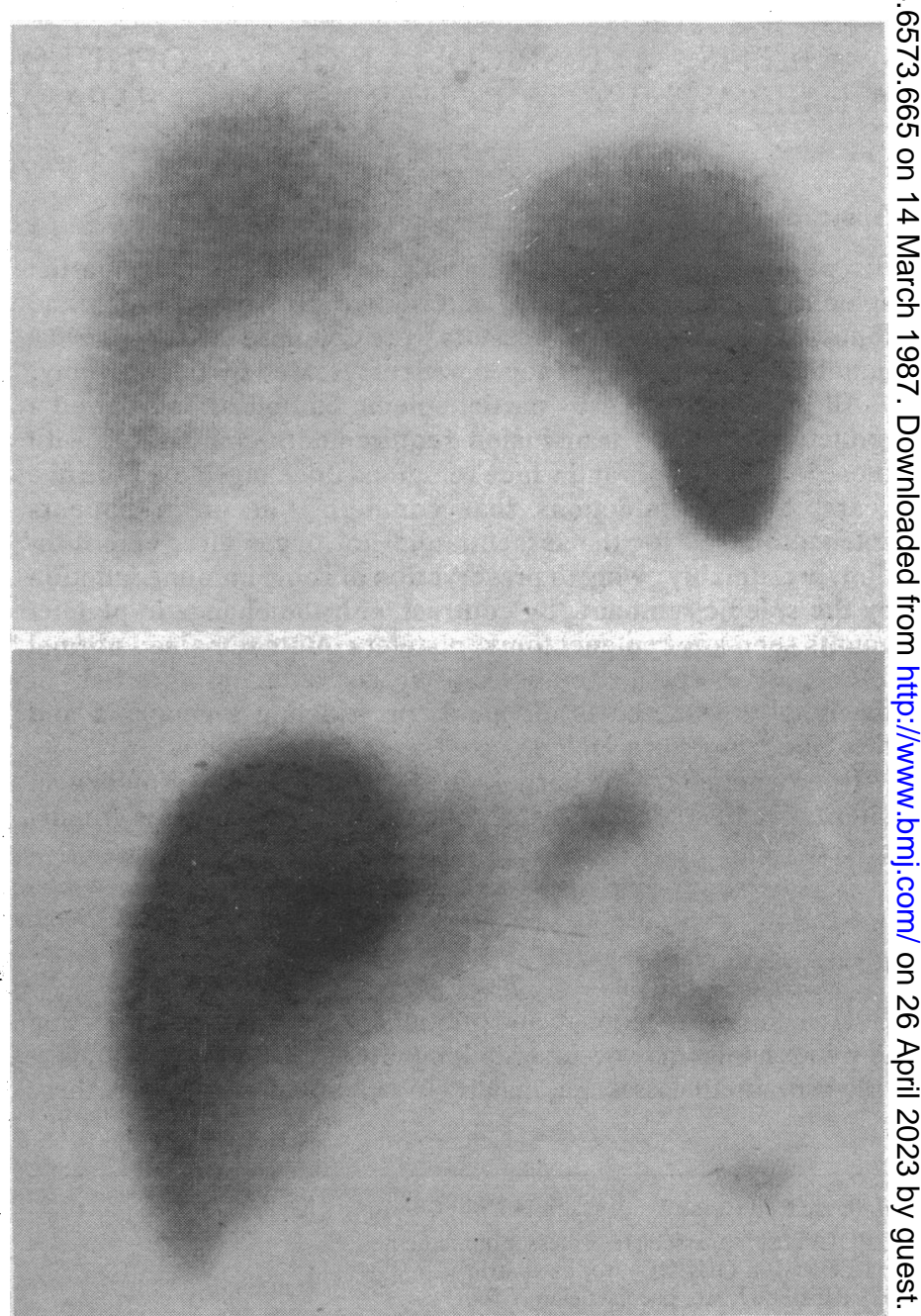

FIG 2-Case 3. Scans of liver and spleen (anterior view) before (top) and after (bottom) partial splenic embolisation.

concentrations of both groups were significantly lower than before the procedures $(p<0.01)$. At no time during follow up was any significant difference in iron load detected between the two groups.

A significant prolongation $(p=0.025)$ of red cell survival was detected one year after partial splenic embolisation (mean increase in half life 5.64 days). 
Patients in the splenectomy group refused red cell survival studies after operation.

Throughout the years after partial splenic embolisation the spleens remained about one third of their original size. A transient, small increase in size was observed during the first month after the procedure. Liver size remained unchanged in both groups of patients.

Patients treated by partial splenic embolisation remained free of serious infections or other illnesses during follow up and showed almost normal puberty and growth. By contrast, two of the patients with splenectomy suffered recurrent infections.

\section{Discussion}

Successful partial splenic embolisation in other diseases ${ }^{5}$ encouraged us to use this procedure for patients with thalassaemia major in an attempt to overcome the disadvantages of splenectomy. Partial splenic embolisation was followed by a significant prolongation of red cell survival, while the fall of the transfusion index, though slightly smaller than after splenectomy, was not significantly different from that in the splenectomised controls. That these low transfusion indices remained unchanged throughout the five years of follow up is convincing evidence that the procedure may be an effective alternative to splenectomy in thalassaemia major.

Furthermore, that the amount of residual splenic tissue remained unchanged suggests that regeneration had not taken place and therefore that hypersplenism was unlikely to develop in the near future. Should this assumption prove false further partial splenic embolisation could be carried out. Partial splenic embolisation represents an easily repeatable and accurately titrable procedure. Such a second embolisation was required in one of our patients because the proportion of spleen infarcted the first time was too low.

The normal platelet counts during the years after partial splenic embolisation represent another important advantage of the procedure, by which the threat of postsplenectomy embolisms and the subsequent use of antiplatelet factors might be avoided. Partial splenic embolisation, however, was as effective as splenectomy in correcting pre-existing thrombocytopenia, at least in the one patient in our series with this problem.

The absence of serious recurrent infections in our patients treated by embolisation together with their normal growth suggests that the immune function of the spleen may be preserved by the remaining tissue.

The failure of our patients to achieve a negative iron balance despite the reduction of their transfusion index may be attributed to their overestimating the positive effect of partial splenic embolisation alone and so reducing the iron chelation treatment. The decreasing ferritin concentrations, however, suggest that patients will reach negative iron balance eventually.

In conclusion, the results of this five year follow up suggest that partial splenic embolisation may prove to be a safe and reliable alternative to splenectomy in the management of thalassaemia major.

\section{References}

1 Modell B, Berdoukas V. The clinical approach to thalassaemia. New York: Grune and Stratton, 1984 2 Smith CH, Erlandson ME, Stern G, Hilgartner MW. Postsplenectomy infection in Cooley's anemia. Ann NY Acad Sci 1964;119:748-57.

3 Eraklis AJ, Kevy SV, Diamond LK, Cross RE. Hazard of overwhelming infection after splenectomy in childhood. N Engl F Med 1967;276:1225-9.

4 Fucharoen S. Hypoxaemia and the effect of aspirin in thalassaemia. Southeast Asian $\mathcal{F}$ Trop Med Public Health 1981;12:90-3.

5 Spigos DG, Jonasson O, Mozew M, Capek V. Partial splenic embolization in the treatment of hypersplenism. Am J Roentgenol 1979;132:777-82.

(Accepted 15 January 1987)

\title{
Predictive value of plasma human chorionic gonadotrophin $\beta$ subunit in diagnosing ectopic pregnancy after in vitro fertilisation and embryo transfer
}

\author{
S H OKAMOTO, D L HEALY, L M MORROW, P A W ROGERS, A O TROUNSON, \\ E C WOOD
}

\section{Abstract}

A study was conducted aimed at establishing a range of plasma concentrations of the $\beta$ subunit of human chorionic gonadotrophin that might predict ectopic pregnancy after in vitro fertilisation and embryo transfer. From May 1984 to February 1986, 161 consecutive pregnancies at the Monash University in vitro fertilisation unit were analysed by determining plasma $\beta$ human chorionic gonadotrophin concentrations between two and 10 weeks after oocyte collection. Eighty eight ongoing singleton pregnancies, 25 multiple pregnancies, 27 first trimester spontaneous abortions, 12 anembryonic pregnancies, and nine ectopic pregnancies resulted from these conception cycles. When compared with values for ongoing singleton pregnancies two weeks after oocyte collection plasma $\beta$ human chorionic gonadotrophin concentrations in ectopic pregnancies were significantly lower $(p<0.05$; Wilcoxon rank sum test). Two weeks after oocyte collection all plasma $\beta$ human chorionic gonadotrophin concentrations in the set of ectopic pregnancies were below 30.6 IU/1, which corresponded to the lower quartile (25th percentile) of $\beta$ human chorionic gonadotrophin concentrations in ongoing singleton pregnancies. The $\beta$ human chorionic gonadotrophin concentration corresponding to the lower quartile of ongoing singleton pregnancies at each week of gestation was used to derive the predictive value of various statistics in detecting ectopic pregnancy in patients after in vitro fertilisation. The sensitivity, specificity, predictive value of a positive result, predictive value of a negative result, and efficiency of a single plasma $\beta$ human chorionic gonadotrophin concentration in predicting ectopic pregnancy were $100 \%$, $68 \cdot 1 \%, 16 \cdot 7 \%, 100 \%$, and $70 \%$, respectively, two weeks after oocyte collection.

These results suggest that a single determination of the plasma $\beta$ human chorionic gonadotrophin concentration beginning 14 days after oocyte collection is clinically useful in predicting the outcome of pregnancy achieved by in vitro fertilisation. Ectopic pregnancy after in vitro fertilisation is more likely when $\beta$ human chorionic gonadotrophin concentration is below the lower quartile of values in ongoing singleton pregnancies achieved by the technique.

\section{Introduction}

Ectopic pregnancy is a leading cause of maternal mortality, and reports show that the ratio of ectopic pregnancy to live births 